\title{
MicroRNA-7 inhibits proliferation, migration and invasion of thyroid papillary cancer cells via targeting CKS2
}

\author{
KAIYAO HUA $^{1,2}$, JIALI JIN ${ }^{3}$, HUIWEN ZHANG $^{2}$, BINGKUN ZHAO ${ }^{1,2}$, \\ CHENYANG WU ${ }^{1}$, HUI XU ${ }^{1}$ and LIN FANG ${ }^{1}$ \\ ${ }^{1}$ Department of Breast and Thyroid Surgery, Shanghai Tenth People's Hospital, \\ Tongji University School of Medicine, Shanghai 200072; ${ }^{2}$ Nanjing Medical University, \\ Nanjing, Jiangsu 210029; ${ }^{3}$ Tongji University School of Medicine, Shanghai 200072, P.R. China
}

Received June 16, 2016; Accepted August 5, 2016

DOI: 10.3892/ijo.2016.3660

\begin{abstract}
The purpose of this study was to examine the expression levels of microRNA-7 (miR-7) in human thyroid papillary cancer and its potential role in disease pathogenesis. The expression levels of different miRNAs were detected by miRNA-microarray analysis in ten thyroid papillary cancer specimens and adjacent normal thyroid cancer tissues. Quantitative reverse transcription-polymerase chain reaction (qRT-PCR) was conducted to determine the expression level of miR-7 in both thyroid papillary cancer tissues and cell lines. To characterize the function of miR-7, MTT assay, colony formation assay, cell migration assay, cell invasion assay, cell cycle assay and cell apoptosis assay were used. Luciferase reporter assays were performed to validate the regulation of a putative target of miR-7, in corroboration with western blot assays. Finally, MTT assay, cell migration assay, cell invasion assay and cell cycle assay were used to indicate the roles of endogenous cyclin-dependent kinase regulatory subunit 2 (CKS2) in thyroid papillary cancer cells. Our results reveal that miR-7 expression was relatively decreased in thyroid papillary cancer specimens and cell lines compared with adjacent normal tissues and normal thyroid cells. Overexpression of miR-7 inhibited cellular proliferation, suppressed cellular migration and invasion, caused a G0/G1 arrest in vitro. Dual-luciferase reporter assays showed that miR-7 binds the 3'-untranslated region (3'-UTR) of CKS2. Western blotting showed that miR-7 negatively regulated CKS2 protein expression. As its downstream genes, cyclin B1 (G2/mitotic-specific cyclin-B1) and cdk1 (cyclin-dependent kinase 1) were regulated by miR-7 and CKS2 axis. Knockdown of CKS2 expression by CKS2-siRNA in TPC1 and K1 cells also significantly suppressed cell prolif-
\end{abstract}

Correspondence to: Dr Kaiyao Hua or Dr Lin Fang, Department of Breast and Thyroid Surgery, Shanghai Tenth People's Hospital, Tongji University School of Medicine, 301 Yanchang Road, Jing'an Area, Shanghai 200072, P.R. China

E-mail: huakaiyao111@163.com

E-mail: 1195097617@qq.com

Key words: miR-7, proliferation, CKS2, thyroid papillary cancer eration, cell migration and invasion. Our results demonstrated for the first time that miR-7 functions as a tumor suppressor and plays an important role in inhibiting the tumorigenesis through targeting CKS2 in thyroid papillary cancer cells.

\section{Introduction}

Thyroid carcinoma (TC) is the most frequent endocrine system tumor and a malignancy with fast growing prevalence rate in recent years. Papillary thyroid carcinoma (PTC) remains the most common pathological type of thyroid malignancy, comprising $\geq 80 \%$ of all thyroid carcinomas $(1,2)$. To date, surgical resection combined with radio iodine and levothyroxine treatment are the primary mode of therapy for patients with PTC (3). Although most PTCs have a good prognosis, regional recurrence is observed in $5-20 \%$ of patients who have undergone total thyroidectomy and lymph node metastasis in the neck occurs in 20-50\% of all patients (4-7). Advanced age at diagnosis, larger primary tumor, extrathyroidal invasion, lymph node metastasis and advanced tumor-node-metastasis (TNM) stage are demonstrated to be associated with a poor prognosis (8). Given this, there is an urgent need to explore the mechanisms involved in the development and progression of thyroid cancers.

MicroRNAs (miRNAs) are a group of endogenous, 19-25 nucleotides non-coding RNAs which can regulate gene expression through binding to the 3 '-untranslated region (3'-UTR) of target genes to promote mRNA degradation or protein translation inhibition (9). Recent evidence has shown that miRNAs are involved in many important physiological and pathological processes, such as cell proliferation, development, differentiation, virus infection and tumorigenesis, and are widely dyregulated in various cancers (10). Nearly half of the human miRNAs are located in cancer-associated genomic regions which are frequently amplified, deleted, or rearranged in cancer, suggesting that miRNAs may function as either tumor-suppresor genes or oncogenes (11). In PTC, miRNA analysis was reported as a potential diagnostic tool, and the miRNA signature was shown to be indicative of the degree of aggressiveness (12). MicroRNA-7 (miR-7) was found to be significantly downregulated in various tumors, including breast cancer (13), lung cancer (14), glioma (15), hepatocellular 
carcinoma (16). In our previous study, miR-7 is downregulated in PTC tissue relative to adjacent normal tissue by miRNAmicroarray analysis conducted in 10 pairs of PTC specimens and normal thyroid tissues. Until now, little was known on the role of miR-7 in PTC, let alone their functions and mechanisms of action.

CKS2, firstly identified in 1990, is located in chromosome 9q22 (17). Accumulated evidence suggests that CKS2 is an oncoprotein that promotes cancer tumorigenesis and progress. It has abnormal expression in a variety of malignant tumor tissues and is closely associated with various biological behavior, such as tumor development, progression and metastasis (18). Previous evidence has demonstrated that CKS2 was regulated by miR-26a in PTC and CKS2 levels were associated with expression of its downstream genes, including cyclin B1 and cdk1 (19). However, there are scarce related research on the function of CKS2 in PTC, and deeper understanding of the post-transcriptional control of the CKS2 gene in PTC remains indefinable.

In this study, we investigated the function of miR-7 in PTC. Interestingly, our experiments demonstrate that upregulation of miR-7 inhibited cellular growth, suppressed cellular migration and invasion, caused a G0/G1 arrest in PTC cells, likely by targeting CKS2. Our results indicate that upregulation of miR-7 level may be a novel therapeutic target for the treatments of thyroid cancer.

\section{Materials and methods}

MiRNA-microarray analysis. In this study, ten paired thyroid papillary cancer specimens and adjacent normal thyroid tissues were collected from the Department of Breast and Thyroid Surgery of Shanghai Tenth People's Hospital, Shanghai, China. All the samples were immediately snap-frozen in liquid nitrogen and confirmed as thyroid papillary cancer by at least two pathologists. None of the patients had received any chemotherapy or radiotherapy before surgery. All the patients participating in the study gave their informed consent and protocols were approved by Institutional Ethics Committees of Tongji University (approval no. SHSY-IEC-pap3.0/13-3).

The ten paired thyroid papillary cancer specimens and adjacent normal thyroid tissues were handled using TRIzol (Invitrogen) and miRNeasy mini kit (Qiagen) according to the manufacturer's instructions. Total RNA $(10 \mu \mathrm{g})$ was size fractionated ( $<200$ nucleotides) by using a mirVana kit (Ambion Inc., Austin, TX, USA) and labeled using the miRCURY' ${ }^{\mathrm{TM}} \mathrm{Hy}^{\mathrm{TM}} / \mathrm{Hy}^{\mathrm{TM}}$ Power labeling kit and hybridized on the miRCURY LNA array (v.16.0). The slides were scanned using the Axon GenePix 4000B microarray scanner. Scanned images were then imported into GenePix Pro 6.0 software (Axon) for grid alignment and data extraction. Data adjustments included data filtering, $\log 2$ transformation, and gene centering and normalization. The t-test analysis was conducted between thyroid papillary cancer specimens and adjacent normal thyroid tissues, and miRNA with P-values $<0.05$ were considered statistically significant.

PTC specimens and cell culture. In our study, 20 pairs of thyroid papillary cancer and adjacent normal specimens were collected from the Department of Breast and Thyroid Surgery of Shanghai Tenth People's Hospital, Shanghai, China. The samples were immediately snap-frozen in liquid nitrogen. Both tumor and normal tissues were histologically confirmed by more than one experienced pathologist according to the World Health Organization (WHO) using H\&E (hematoxylin and eosin) staining, and none of these patients had received any chemotherapy or radiotherapy prior to surgery. Human Nthy-ori 3-1 normal thyroid follicular epithelial cells, human TPC1 thyroid papillary cancer cells, human K1 thyroid papillary cancer cells and human B-CPAP thyroid papillary cancer cells were obtained from the Chinese Science Institute (Shanghai, China). The Nthy-ori 3-1 cells, TPC1 cells and B-CPAP cells were cultured in RPMI-1640 medium (RPMI-1640; Gibco, USA) supplemented with $100 \mathrm{U} / \mathrm{ml}$ penicillin and $100 \mu \mathrm{g} / \mathrm{ml}$ streptomycin (Enpromise, Hangzhou, China), 10\% fetal bovine serum (FBS; Gibco). The K1 cells were cultured in Dulbecco's modified Eagle's medium (DMEM; Gibco) supplemented with $100 \mathrm{U} / \mathrm{ml}$ penicillin and $100 \mu \mathrm{g} / \mathrm{ml}$ streptomycin (Enpromise), $10 \%$ fetal bovine serum (FBS; Gibco). Cells were incubated at $37^{\circ} \mathrm{C}$ in a humidified chamber containing $5 \% \mathrm{CO}_{2}$. Cells at $\sim 90 \%$ confluence were split at 1:3 ratio every 2-3 days.

Transfection assay. All miRNA mimics were chemically synthesized and purified by GenePharma (Shanghai, China) based on the following sequences: hsa-miR-7 mimics: 5'-UGG AAGACUAGUGAUUUUGUUGU-3' , miR-negative control (miR-NC): 5'-UUCUCCGAACGUGUCCGGAGAATT-3'. CKS2-siRNA and its NC were chemosynthesized by Guangzhou RiboBio Co., Ltd. (Guangzhou, China). Cells (1x106) were added into each well of a 6-well plate and cultured with RPMI-1640 or DMEM medium without serum and antibiotics. When the confluency of breast cancer cells reached 30-50\%, miR-7 mimics, CKS2-siRNA and their NC were transfected at working concentrations using Lipofectamine 2000 (Invitrogen, Carlsbad, CA, USA) according to the manufacturer's instructions. After 4-5 h of incubation, RPMI-1640 or DMEM medium was replaced by RPMI-1640 or DMEM with $10 \% \mathrm{FBS}$, and all the cells were incubated at $37^{\circ} \mathrm{C}$ in a $\mathrm{CO}_{2}$ incubator for 48-72 $\mathrm{h}$ prior to further testing.

$R N A$ extraction and quantitative reverse-transcription PCR ( $q R T-P C R$ ). According to the manufacturer's protocol, total RNA was extracted from the cells or tissues using TRIzol (Invitrogen) and stored at $-80^{\circ} \mathrm{C}$. For detection of miR-7 expression, primer design and qRT-PCR were carried out according to the manufacturer's instructions. The primers of miR-7 and U6 were purchased from GenePharma, and U6 was used for normalization. cDNA was generated by reverse transcription using the PrimeScript ${ }^{\mathrm{TM}}$ RT-PCR kit according to the manufacturer's instructions (Takara, Tokyo, Japan). Real-time PCR was performed on a 7900HT Fast RT-PCR instrument (Applied Biosystems, Singapore). The amplification procedure was as follows: $5 \mathrm{~min}$ at $95^{\circ} \mathrm{C}$, followed by 40 cycles at $95^{\circ} \mathrm{C}$ for $30 \mathrm{sec}$ and $65^{\circ} \mathrm{C}$ for $45 \mathrm{sec}$. The relative expression was evaluated following the relative quantification equation, $2^{-\Delta \Delta \mathrm{CT}}$. Each sample was tested in triplicate. Quantitative detection of CKS2 was implemented using the same strategy. The primers used were as followed: CKS2 forward, 5'-TTCGAC GAACACTACGAGTACC-3'; reverse, 5'-GGACACCAAGTC TCCTCCAC-3'. $\beta$-actin forward, 5'-AGCGAGCATCCCCCA 
AAGTT-3'; reverse, 5'-GGGCACGAAGGCTCATCATT-3'. The PCR parameters for relative quantification were as follows: $2 \mathrm{~min}$ at $95^{\circ} \mathrm{C}$, followed by 40 cycles of $45 \mathrm{sec}$ at $57^{\circ} \mathrm{C}$ and $45 \mathrm{sec}$ at $72^{\circ} \mathrm{C}$. The relative expression was evaluated following the relative quantification equation, $2^{-\Delta \Delta C T}$. All qRT-PCRs were performed in triplicates.

Cell proliferation assay (MTT assay). Cell proliferation was determined using the MTT method. Briefly, $24 \mathrm{~h}$ after transfection, the TPC1 and K1 cells were seeded into 96-well culture plates (BD Biosciences, Franklin Lakes, NJ, USA) and incubated overnight at $37^{\circ} \mathrm{C}$ in $5 \% \mathrm{CO}_{2}$. Cell proliferation was assessed at 24, 48, 72, 96 and $120 \mathrm{~h}$ following addition of $0.5 \mathrm{mg} / \mathrm{ml}$ MTT (Sigma, USA) solution. After a 4-h incubation, The reaction was stopped by addition of $150 \mu \mathrm{l}$ DMSO (Sigma). After $10 \mathrm{~min}$ of agitation (100 rpm), the optical density (OD) at $490 \mathrm{~nm}$ was determined with microplate reader (BioTek). Each sample was tested with six replicates. All experiments were performed in biological triplicate.

Plate colony formation assay. Twenty-four hours after transfection, Five hundred TPC1 and K1 cells were seeded in 6-well plates and were incubated at $37^{\circ} \mathrm{C}$. The medium was replaced every 3 days. After 7-10 days, or when the colonies were visible, the culture was terminated. The colonies were washed twice with PBS, fixed with $95 \%$ ethanol for $10 \mathrm{~min}$ and stained with $0.1 \%$ crystal violet for $10 \mathrm{~min}$, then the plate was slowly washed three times with water. When the plate was dried, the number of visible colonies was counted and representative colonies were captured. The number of colonies was counted only if the colony contained $>50$ cells. Each experiment was performed in triplicate.

Wound healing assay. In the in vitro wound healing assay, TPC1 and K1 cells were cultured in 6-well plates until the cell confluence reached $\sim 90 \%$. Then the plates were washed in PBS after making a scratch in each well using a sterile pipette tip. Wound healing was observed under a light microscope and images were captured at the same view at $0,12,24$ and $48 \mathrm{~h}$ after scratching to observe the process of wound healing. The experiments were repeated twice and representative images are shown.

Transwell invasion assay. A Transwell invasion assay was performed by using Chemicon Cell Invasion assay kit (Chemicon, USA). Cells $\left(5 \times 10^{4}\right.$ cells/Transwell) were plated in the top chamber of Transwells with a Matrigel $(2 \mathrm{mg} / \mathrm{ml})$-coated membrane with $8-\mu \mathrm{m}$ diameter pores in $200 \mu 1$ serum-free DMEM. The lower chambers were filled with $500 \mu \mathrm{l}$ of DMEM containing 10\% FBS. After $48 \mathrm{~h}$ of incubation, the membrane was stained with $0.1 \%$ crystal violet and observed under a microscope after removing the Matrigel and cells in the upper chambers. Five fields were randomly selected from each membrane, and the number of cells penetrating the membrane was counted at a magnification of x200. The invasion ability was described as the number of invading cells. Each experiment was carried out in triplicate. Membrane-binding crystal violet was dissolved with $400 \mu \mathrm{l}$ $33 \%$ glacial acetic acid, and then absorbance at $573 \mathrm{~nm}$ was measured using a microplate reader.
Cell cycle assay and apoptosis assay. For all groups, $10^{6}$ cells were collected in PBS and resuspended in $70 \%$ ethanol to fix overnight at $4^{\circ} \mathrm{C}$. Cells were pelleted at $1,000 \mathrm{rpm} / \mathrm{min}$ for $5 \mathrm{~min}$, washed in PBS, and then pelleted at $1,000 \mathrm{rpm} / \mathrm{min}$ for $5 \mathrm{~min}$. A total of $250 \mu \mathrm{l} 0.05 \mathrm{~g} / \mathrm{l}$ propidium iodide (PI) staining solution was added into each sample and incubated for $30 \mathrm{~min}$ at room temperature, and cell cycle distribution was analyzed using flow cytometry (FACSCanto ${ }^{\mathrm{TM}}$ II, BD Biosciences). For cell apoptosis assay, cells transfected with miR-7 and negative control were incubated in 6-well plates for $24 \mathrm{~h}$. Cells were subsequently stained with fluorescein (FITC)-conjugated Annexin V and propidium iodide (FITC-Annexin V/PI) (BD Biosciences, San Diego, CA, USA), the rate of apoptosis was detected by flow cytometry (FACSCanto II, BD Biosciences).

Dual-luciferase reporter assay. 293T cells were seeded in 12-well plates (BD, USA) and cultured until the cells reached $80-90 \%$ confluence. The CKS2 3'-UTR was cloned into the psiCHECK-2 vector containing the RL gene, and co-transfected into cells together with miR-7 mimics or negative control $(100 \mathrm{nM})$ using Lipofectamine 2000 (Invitrogen) according to the manufacturer's instructions. Thirty-six hours after transfection, luciferase activity was measured using the dual-luciferase reporter assay kit (Promega, Madison, WI, USA). Briefly, the cells were washed twice with PBS and lysed by incubation on ice for 30 min with passive lysis buffer (PLB, $250 \mu \mathrm{l} / \mathrm{well}$ ). The supernatants were collected, and $20 \mu 1$ of the aliquots were added to $96-$ well plates. The firefly luciferase (FL) reporter was measured by a microplate spectrophotometer immediately after adding $50 \mu \mathrm{l}$ of Luciferase Assay Reagent II. Next, Stop \& Glo ${ }^{\circledR}$ reagent $(50 \mu \mathrm{l} /$ well $)$ was added to each well to initiate the Renilla luciferase (RL). RL activity was normalized to FL activity. All experiments were performed three times.

Western blot analysis. Cells were washed in ice-cold PBS and resuspended in RIPA lysis buffer (100 $\mu \mathrm{l} /$ well, Beyotime). Then the cells were collected and centrifuged for $30 \mathrm{~min}$ at $4^{\circ} \mathrm{C}$ (Eppendorf 5804R, Eppendorf Biotech, Germany). Supernatants were collected and the protein concentrations were quantified using a BCA protein assay kit (Beyotime). Protein samples were denatured with 5X SDS loading buffer (Beyotime) at $100^{\circ} \mathrm{C}$ for $10 \mathrm{~min}$. Next, whole protein samples were separated by $8 \%$ SDS-polyacrylamide gel electrophoresis (SDS-PAGE) and transferred onto $0.45-\mu \mathrm{m}$ nitrocellulose membranes (Beyotime). After $1 \mathrm{~h}$ of blocking in 5\% fat-free milk, the membranes were incubated with the CKS2 $(1: 1,000)$, cyclin B1 $(1: 1,000)$, cdk1 $(1: 1,000)$, cyclin A $(1: 1,000)$ and the $\beta$-actin (1:1,500) antibody (all from Cell Signaling Technology, USA) overnight at $4^{\circ} \mathrm{C}$. Protein blots were washed and then incubated for $1 \mathrm{~h}$ with specific secondary antibodies. After washing by PBST 3 times, immunoreactive protein bands were detected using the Odyssey scanning system (LI-COR, Lincoln, NE, USA).

Statistical analysis. Data were presented as the means \pm standard deviation (SD) from at least three independent experiments. The Students t-test was used to evaluate the differences between each group in SPSS 20.0 software. Differences were considered significant for P-values $<0.05$. 

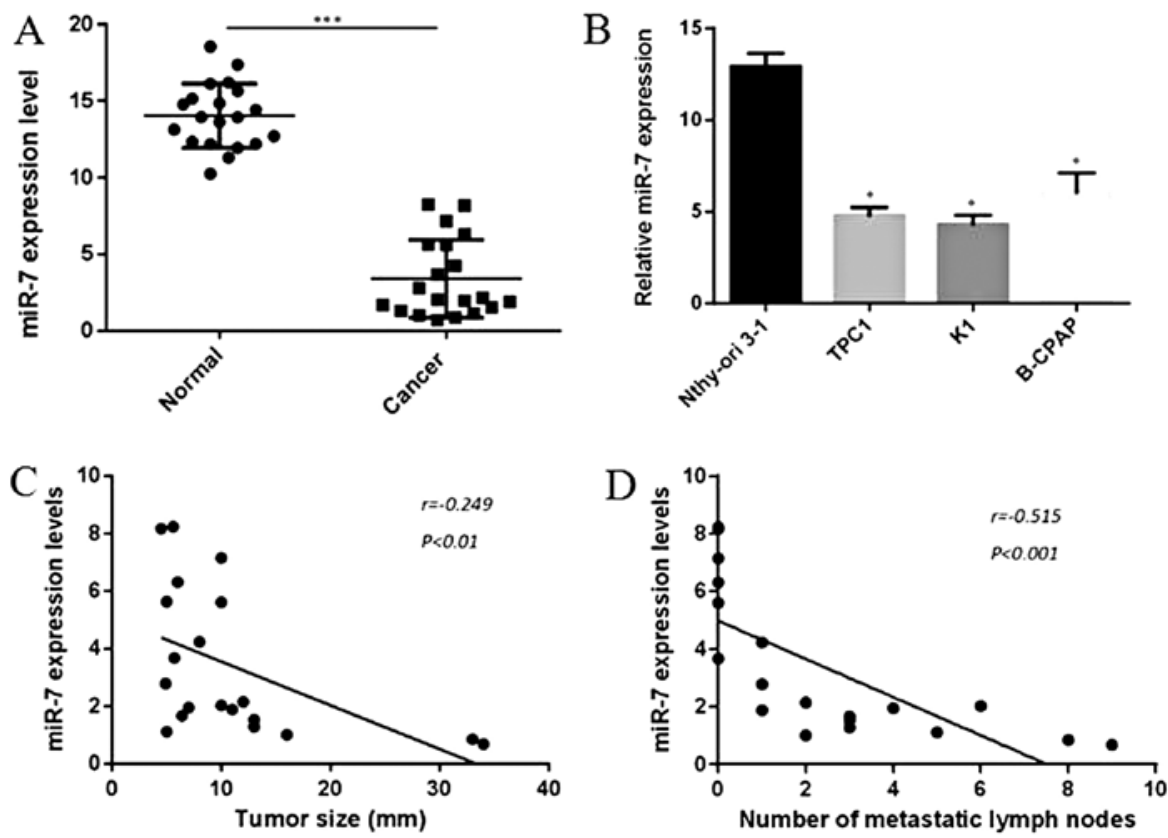

Figure 1. miR-7 is downregulated in human thyroid papillary cancer clinical specimens and cell lines. The levels of miR-7 were measured by qRT-PCR and normalized to the expression of U6. (A) Relative miR-7 expression in 20 paired thyroid papillary cancer tissues and matched adjacent normal breast tissues. ${ }_{* * * *} \mathrm{P}<0.001$ cancer vs. normal. (B) Relative expression of miR-7 in thyroid papillary cancer cell lines TPC1, K1 and B-CPAP compared to Nthy-ori 3-1. Data represent the $2^{-\Delta \Delta C t}$ values $\pm S D$; ${ }^{*} \mathrm{P}<0.05$ vs. Nthy-ori 3-1. (C) A negative correlation between the tumor size and the miR-7 expression level. $\mathrm{r}=-0.249, \mathrm{P}<0.01$. (D) A negative correlation between the number of metastatic lymph nodes and the miR-7 expression level. $\mathrm{r}=-0.515, \mathrm{P}<0.001$.

\section{Results}

miR-7 is downregulated in both human thyroid papillary cancer specimens and cell lines. In our experiment, miRNAmicroarray was first performed to analyze the miRNA expression between thyroid papillary cancer tissues and paracancer tissues. As shown in Table I, expression of 83 miRNAs was upregulated and 75 miRNAs were downregulated with a $\mathrm{P}$-value $<0.05$. We also found that the expression of miR-7 was significantly decreased in cancer tissues compared to paracancer tissues, nearly 5.64-fold change. Our results were partly consistent with the findings of Pallante et al (20). To explore the role of miR-7 in human thyroid papillary carcinomas, we further analyzed 20 pairs of thyroid papillary cancer and adjacent normal specimens in this study. Total RNAs were isolated from excised tumor tissues and benign tissues of patients with thyroid papillary cancer. Detection of miR-7 by qRT-PCR indicated that miR-7 levels were obviously downregulated in thyroid papillary cancer tissues compared with benign tissues, which was consistent with our finding in miRNA-microarray $(\mathrm{P}<0.001$, Fig. 1A). Moreover, expression of miR-7 was also demontrated to be downregulated in three collected thyroid papillary cancer cell lines compared to Nthy-ori 3-1, a normal thyroid follicular epithelial cell line $(\mathrm{P}<0.05$, Fig. 1B). In this experiment, we also explored the relationship between clinical features and miR-7 expression levels, in our case, a negative correlation was found between tumor size and miR-7 expression levels ( $\mathrm{r}=-0.249, \mathrm{P}<0.01$, Fig. 1C), as well as number of metastatic lymph nodes and miR-7 expression levels $(r=-0.515$, $\mathrm{P}<0.001$, Fig. 1D). These findings imply a potential role in tumor growth and metastasis of miR-7 in thyroid papillary cancer.
Table I. Differential expression of miRNAs in thyroid papillary cancer specimens compared with para-cancer tissues. ${ }^{\text {a }}$

\begin{tabular}{|c|c|c|c|}
\hline & MicroRNA & Fold change & P-value \\
\hline \multirow[t]{14}{*}{ Upregulated } & hsa-miR-135b & 7.89 & 0.011 \\
\hline & hsa-miR-142 & 6.76 & 0.044 \\
\hline & hsa-miR-146b & 11.70 & $3.12 \mathrm{e}^{-5}$ \\
\hline & hsa-miR-15a & 9.11 & 0.002 \\
\hline & hsa-miR-19a-3p & 5.85 & 0.043 \\
\hline & hsa-miR-200a & 7.90 & 0.036 \\
\hline & hsa-miR-200b & 9.62 & 0.011 \\
\hline & hsa-miR-21 & 5.64 & $4.34 \mathrm{e}^{-6}$ \\
\hline & hsa-miR-221 & 8.16 & $3.11 \mathrm{e}^{-6}$ \\
\hline & hsa-miR-222 & 8.33 & $1.49 \mathrm{e}^{-5}$ \\
\hline & hsa-miR-301a & 3.86 & 0.002 \\
\hline & hsa-miR-31 & 5.76 & $1.55 \mathrm{e}^{-5}$ \\
\hline & hsa-miR-429 & 6.86 & 0.009 \\
\hline & hsa-miR-96 & 5.45 & 0.008 \\
\hline \multirow[t]{11}{*}{ Downregulated } & hsa-miR-144 & 3.04 & $7.36 \mathrm{e}^{-4}$ \\
\hline & hsa-miR-193b-5p & 3.73 & $2.84 \mathrm{e}^{-4}$ \\
\hline & hsa-miR-197 & 7.30 & 0.004 \\
\hline & hsa-miR-204 & 3.62 & 0.005 \\
\hline & hsa-miR-424 & 3.04 & 0.001 \\
\hline & hsa-miR-451a & 9.60 & $4.10 \mathrm{e}^{-7}$ \\
\hline & hsa-miR-486 & 3.57 & $7.90 \mathrm{e}^{-4}$ \\
\hline & hsa-miR-494 & 6.07 & 0.001 \\
\hline & hsa-miR-7 & 5.64 & 0.002 \\
\hline & hsa-miR-718 & 3.21 & 0.020 \\
\hline & hsa-miR-887 & 3.04 & $1.86 \mathrm{e}^{-5}$ \\
\hline
\end{tabular}

a83 miRNAs are upregulated and 75 miRNAs are downregulated with a P-value $<0.05$. Some of the unregulated miRNAs are listed, as well as the fold change and P-value. 

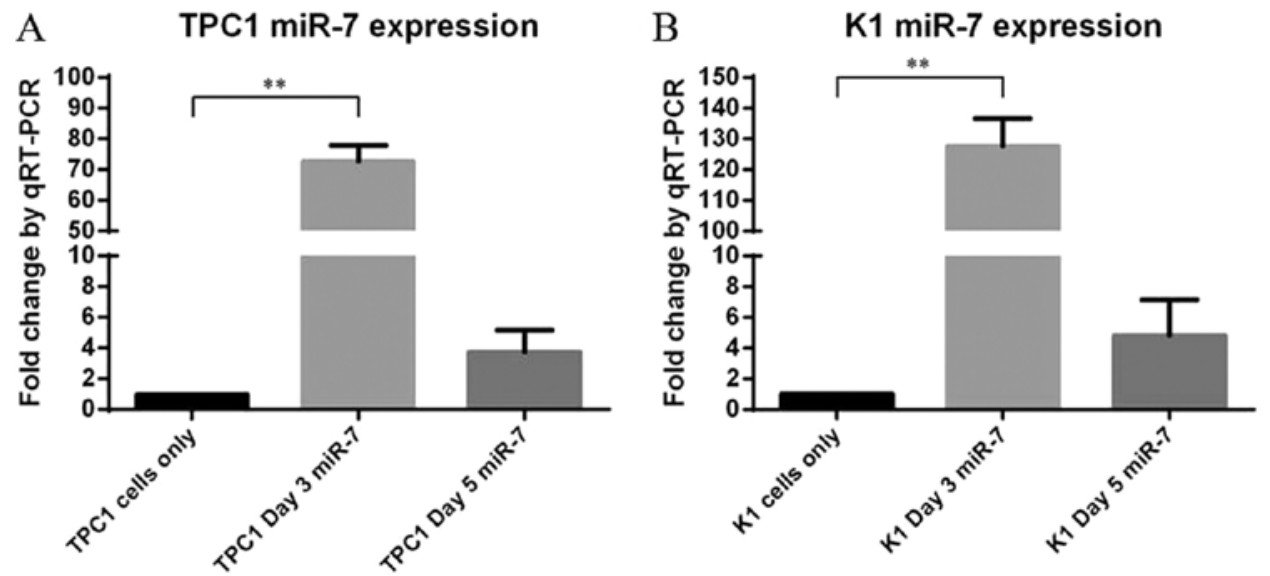

Figure 2. miR-7 expression levels after transfection. (A and B) Expression levels of miR-7 in cell lines TPC1 and K1 three and five days after transfection with miR-7 mimics. Relative miR-7 expression was detected by qRT-PCR. Data represent the $2^{-\Delta \Delta C t}$ values $\pm \mathrm{SD} ;{ }^{* * *} \mathrm{P}<0.01 \mathrm{vs}$. TPC1 cells only, ${ }^{* *} \mathrm{P}<0.01 \mathrm{vs} . \mathrm{K} 1 \mathrm{cells}$ only.
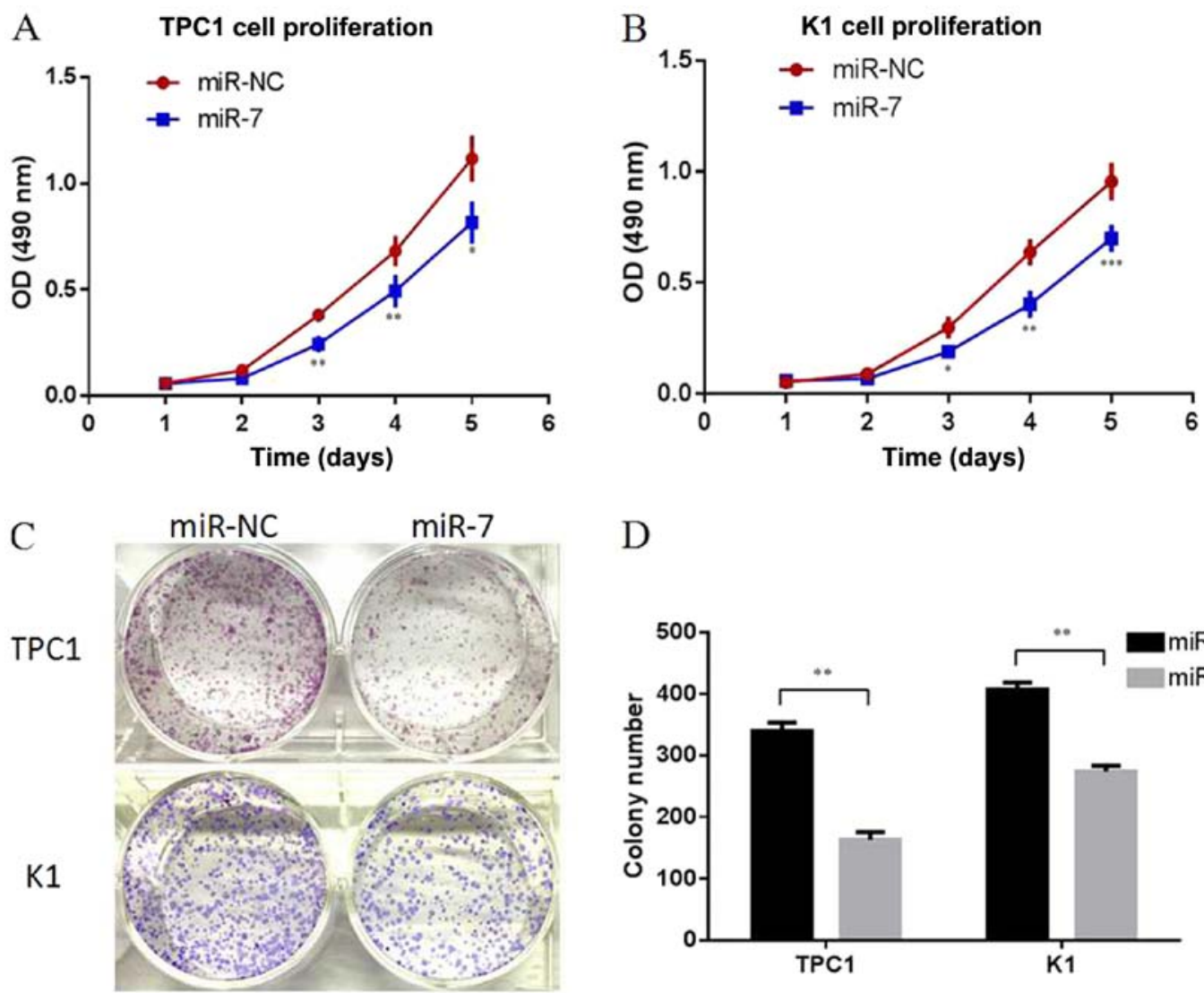

$\mathrm{D}$

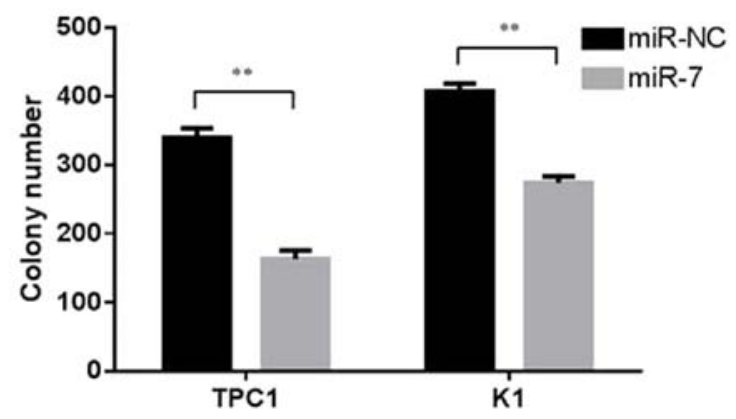

Figure 3. TPC1 and K1 cell proliferation was reduced after miR-7 transfection compared to miR-NC. (A and B) TPC1 and K1 cells were transfected with $100 \mathrm{nmol} / \mathrm{l} \mathrm{miR-7} \mathrm{mimics.} \mathrm{MTT} \mathrm{assay} \mathrm{was} \mathrm{performed} \mathrm{to} \mathrm{monitor} \mathrm{the} \mathrm{proliferation} \mathrm{level} \mathrm{of} \mathrm{cells} \mathrm{at} \mathrm{1,} \mathrm{2,3,4} \mathrm{and} 5$ days. Data represent OD $490 \mathrm{~nm} \pm \mathrm{SD}$; ${ }^{*} \mathrm{P}<0.05,{ }^{* * *} \mathrm{P}<0.01,{ }^{* * * *} \mathrm{P}<0.001$ vs. miR-NC. (C) Colony formation assay showed much less colony formation in the group transfected with miR-7 mimics compared with the miR-NC group. Representative images are shown. (D) Colony number of TPC1 and $\mathrm{K} 1$ cells. ${ }^{* * *} \mathrm{P}<0.01 \mathrm{vs}$. miR-NC.

miR-7 inhibits the proliferation of thyroid papillary cancer cells in vitro. As two of the most representative thyroid papillary cancer cell lines, TPC1 and K1 cells were selected in our following experiments. To explore the role of endogenous miR-7 in thyroid papillary cancer, miR-7 was overexpressed in the TPC1 and K1 cells by transiently transfecting with miR-7 mimics, and scrambled miRNA sequences (miR-NC) were used as negative control. Following transfection, increased miR-7 expression was confirmed by qRT-PCR $(\mathrm{P}<0.01$, Fig. 2). Cell proliferation assay (MTT assay) indicated that overexpression of miR-7 resulted in significant inhibition of cell proliferation in both TPC1 and $\mathrm{K} 1$ cells $(\mathrm{P}<0.05, \mathrm{P}<0.01$, $\mathrm{P}<0.001$, Fig. 3A and B). Colony formation assays also showed less colony formation in the group transfected with miR-7 

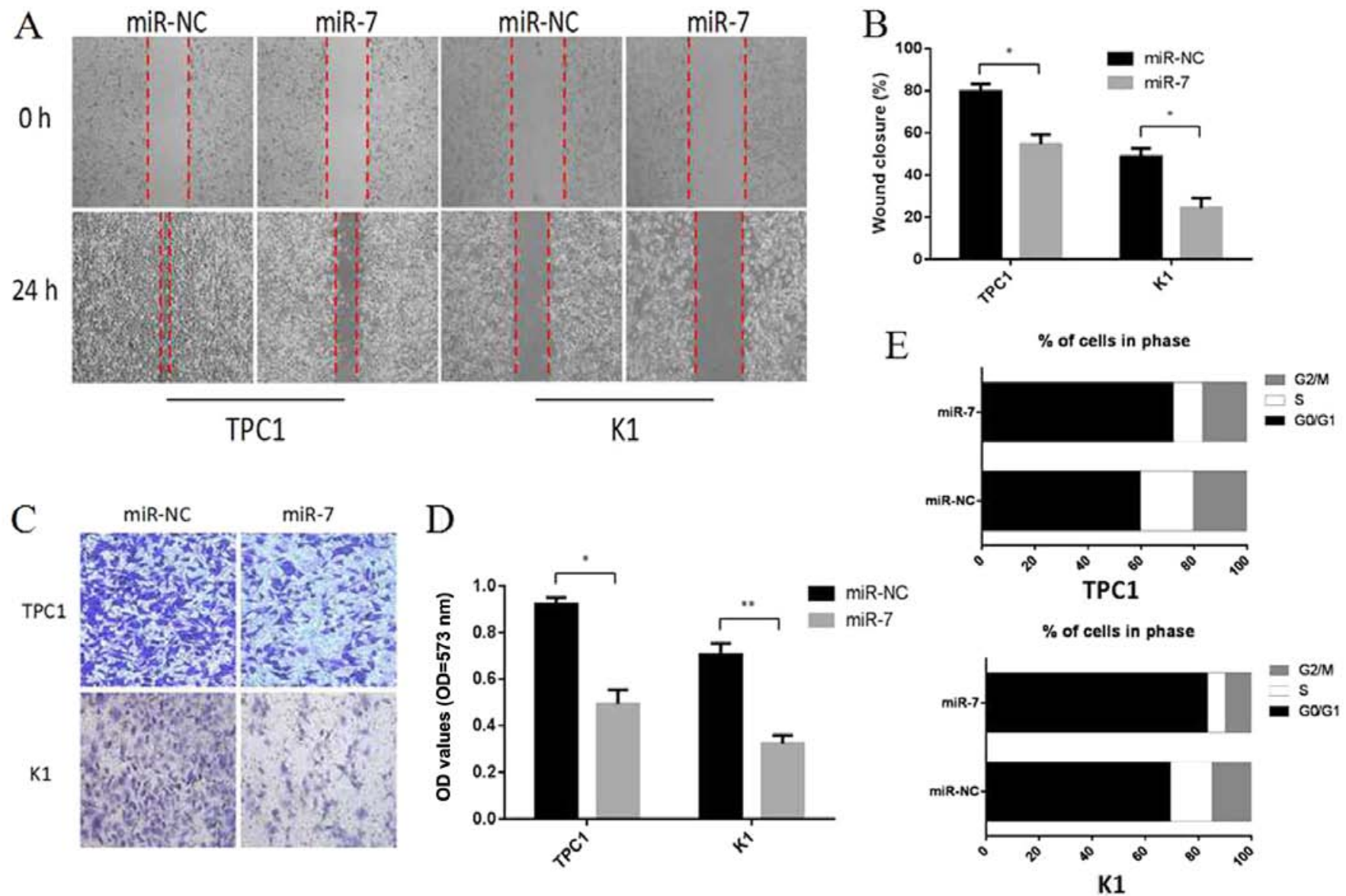

Figure 4. miR-7 inhibits TPC1 and K1 cell migration and invasion. miR-7 induces a G0/G1 arrest. (A) We transfected TPC1 and K1 cells with 100 nmol/1 miR-7 mimics and detected changes in their motility using wound healing assay. Representative images are shown. (B) Percentage wound closure was calculated using edge detection and area calculation with ImageJ software. "P<0.05 vs. miR-NC. (C) We transfected TPC1 and K1 cells with $100 \mathrm{nmol} / 1 \mathrm{miR}-7 \mathrm{mimics}$ and detected changes in their motility using Transwell invasion assays. Representative images are shown. (D) Crystal violet was dissolved with glacial acetic acid, and then absorbance at $573 \mathrm{~nm}$ was measured using a microplate reader. ${ }^{*} \mathrm{P}<0.05,{ }^{* *} \mathrm{P}<0.01$ vs. miR-NC. (E) Effects of miR-7 on cell cycle in TPC1 and $\mathrm{K} 1$ cell. G0/G1 phase of cell cycle was increased by a mean $13.4 \%$ in TPC1 cells and increased by a mean $14.1 \%$ in K1 cells in miR-7 treated cells compared to miR-NC treated cells. S phase was reduced by a mean $9.4 \%$ in TPC1 cells and reduced by a mean $9.1 \%$ in K1 cells in miR-7 treated cells compared to miR-NC treated cells. Cell cycle was assessed using flow cytometry with PI staining by three experiments. P<0.05 vs. miR-NC.

mimics compared with the miR-NC group $(\mathrm{P}<0.01$, Fig. 3C and D). Our data indicated that miR-7 can inhibit cell proliferation in thyroid papillary cancer cells in vitro.

miR-7 inhibits thyroid papillary cancer cell migration and invasion in vitro. To further elucidate the functional role of miR-7 in thyroid papillary cancer, we assessed the impact of its overexpression on metastatic processes, wound healing assays and Transwell assays were performed in TPC1 and $\mathrm{K} 1$ cells. Cells were transiently transfected with miR-7 mimics or miR-NC. As shown in Fig. 4A and B, $24 \mathrm{~h}$ after drawing the 'scratch' line on the monolayer TPC1 cells, the miR-NC group nearly filled in the gap, while the miR-7 group still showed a clear gap in the scratched region, and the experiments carrying out in K1 cells also showed a similar trend. Percentage wound closure was calculated using edge detection and area calculation with ImageJ software $(\mathrm{P}<0.05)$. The results indicate that overexpression of miR-7 in TPC1 and K1 cells can inhibit cellular migration. The Transwell invasion assay revealed that the number of TPC 1 and $\mathrm{K} 1$ cells penetrating the membrane significantly decreased at $48 \mathrm{~h}$ after miR-7 mimics transfection as compared to the miR-NC group $(\mathrm{P}<0.05, \mathrm{P}<0.01$, Fig. $4 \mathrm{C}$ and D). Taken together, these results showed that overexpression of miR-7 can inhibit cellular migration and invasion in vitro.

miR-7 regulates the cell cycle of thyroid papillary cancer cells. The reason of the reduction in cell proliferation following miR-7 overexpression was explored by using cell division and cell apoptosis analysis. Cell division analysis detected by flow cytometry revealed that TPC1 and K1 cells transfected with miR-7 had a significantly reduced percentage in $\mathrm{S}$ and $\mathrm{G} 2 / \mathrm{M}$ phase and an increase in G0/G1 phase compared to miR-NC transfected cells $(\mathrm{P}<0.05$, Fig. 4E). Cell death analysis using apoptosis assays showed no significant changes in the cell population transfected with miR-7 compared to miR-NC group ( $\mathrm{P}>0.05$, data not shown). These findings revealed that miR-7 can lead to upregulation of G0/G1 phase cells and we propose that miR-7 acts to reduce cell proliferation partly by inducing G0/G1 cell cycle arrest in thyroid papillary cancer.

miR-7 regulates the expression of CKS2 and its downstream genes. To investigate the mechanism of miR-7 in thyroid papillary cancer, we screened the target genes of miR-7 by using 

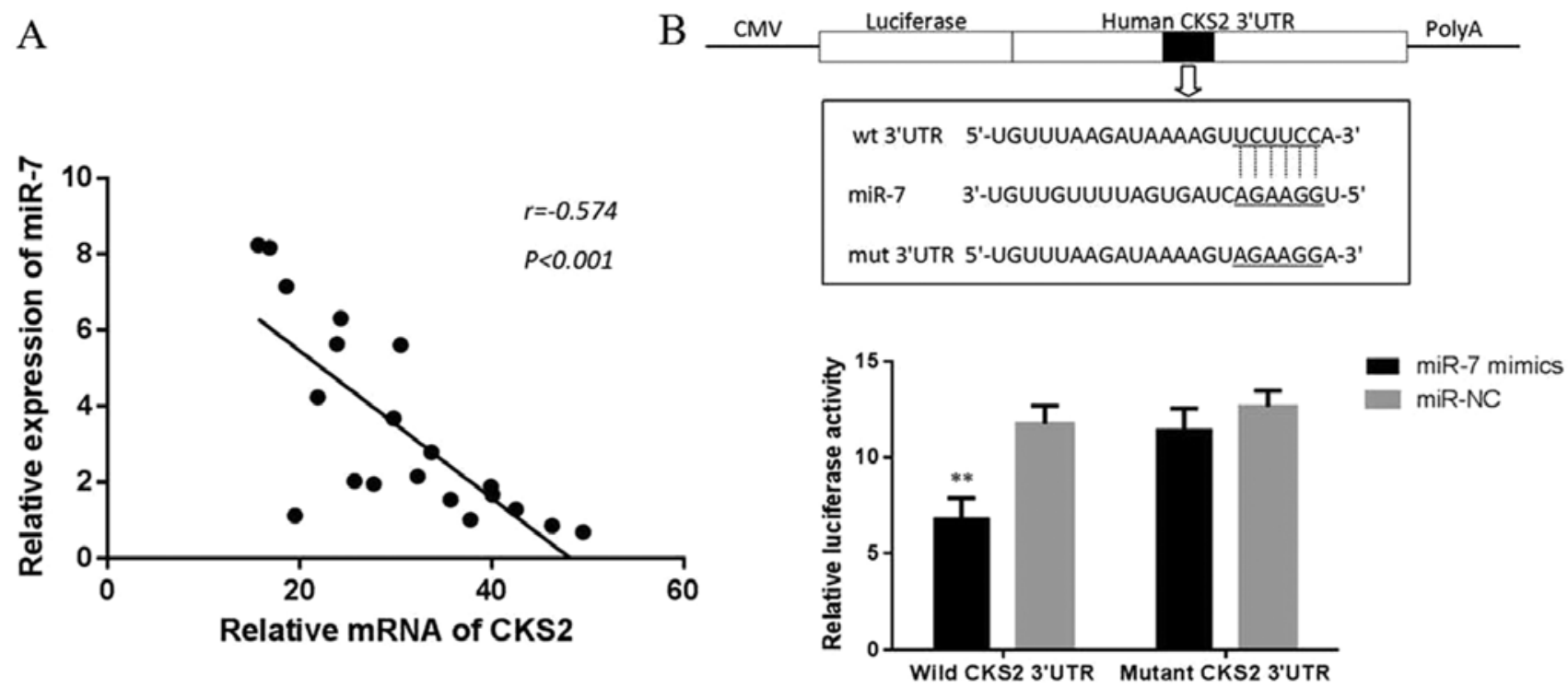

Figure 5. CKS2 is a direct target of miR-7. (A) miR-7 levels were found to be markedly inversely correlated with CKS2 expression in clinical thyroid papillary cancer specimens. $\mathrm{r}=-0.574, \mathrm{P}<0.001$. (B) The binding site for miR-7 in the 3'-UTR of CKS2 3 '-UTR. The relative luciferase activity was measured in 293T cells after co-transfection of the CKS2 3'-UTR or CKS2 3'-UTR mutant luciferase construct with either miR-7 mimics or miR-NC. Data represent means $\pm \mathrm{SD} ;{ }^{* *} \mathrm{P}<0.01$ vs. miR-NC.

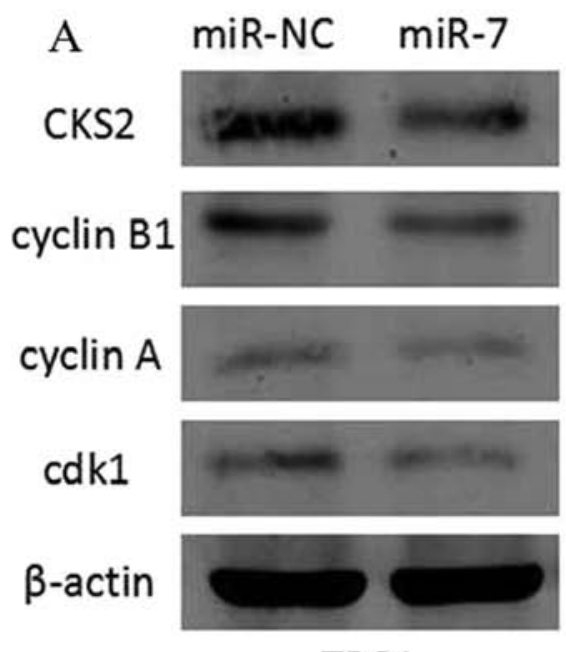

TPC1
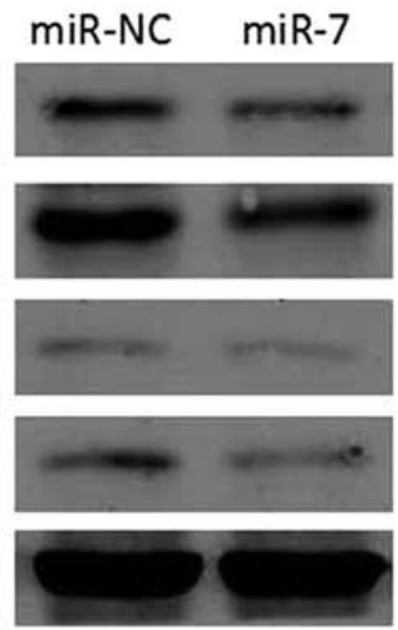

K1

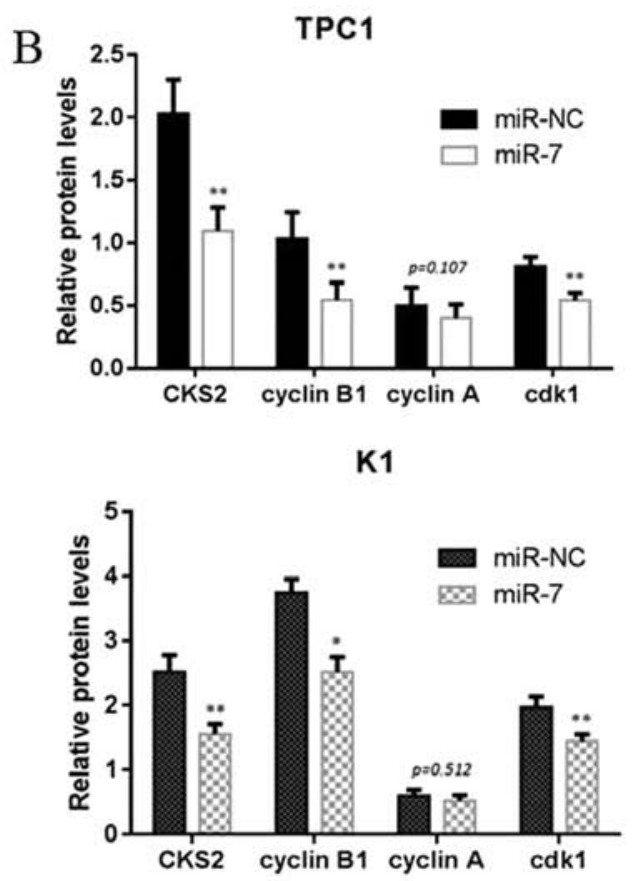

Figure 6. Following miR-7 transfection in TPC1 and K1 cells, reduced mean protein expression of CKS2, cyclin B1 and cdk1 was detected compared to miR-NC treated cells. (A) Representative images of one experiment are shown. $\beta$-actin was used as a control for loading the western blots. (B) Relative protein levels were calculated from mean densitometry measurement taken from three experiments. ${ }^{*} \mathrm{P}<0.05,{ }^{* *} \mathrm{P}<0.01 \mathrm{vs}$. miR-NC.

Targetscan and microRNA.org (http://www.targetscan.org/ and http://www.microrna.org). CKS2 (also referred to as CDC28 protein kinase regulatory subuinit2, or $\mathrm{Cks} 2$ ), a member of cell cycle dependent protein kinase subunits family, was identified as a candidate. Then, we explore the correlation between the expression of miR-7 and CKS2 in 20 collected clinical thyroid papillary cancer specimens. Interestingly, miR-7 levels were found to be markedly inversely correlated with CKS2 expression ( $r=-0.574, \mathrm{P}<0.001$, Fig. 5A), suggesting that miR-7 might target CKS2 mRNA in thyroid papillary cancer. To verify whether miR-7 can bind to the predicted site of CKS2, we performed luciferase reporter assay in the $293 \mathrm{~T}$ cell line. As shown in Fig. 5B, the luciferase activity significantly decreased after co-transfection with psi-CHECK-2/CKS2 3'-UTR and miR-7 mimics in comparison with control cells, indicating that miR-7 specifically binds to the 3'-UTR of CKS2 mRNA. In addition, we analyzed the level of CKS2 expression in TPC1 and $\mathrm{K} 1$ cells transfected with miR-7 mimic or miR-NC by 
A
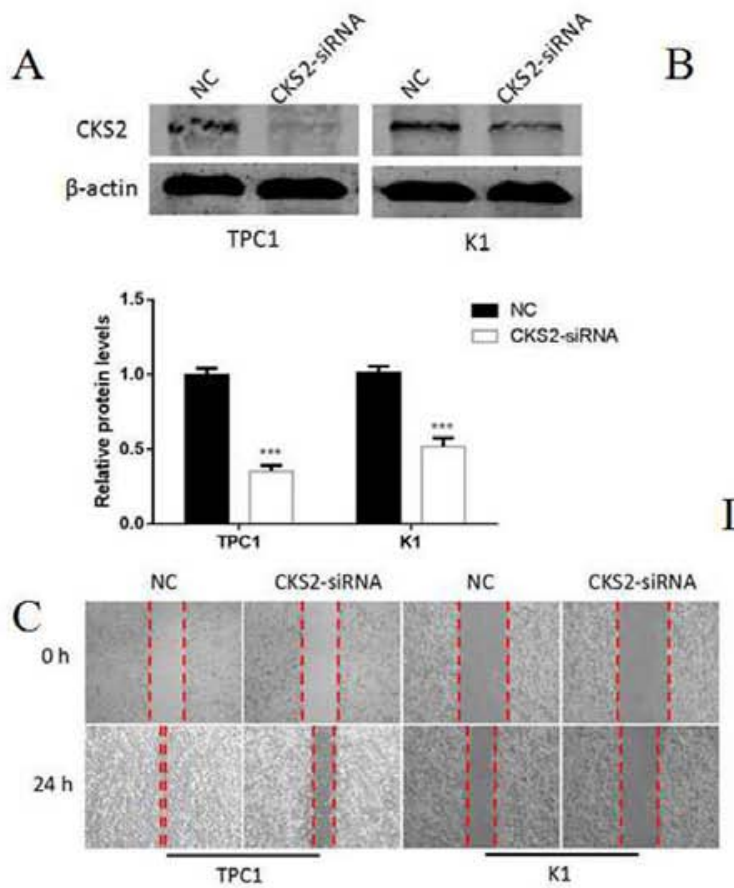

B

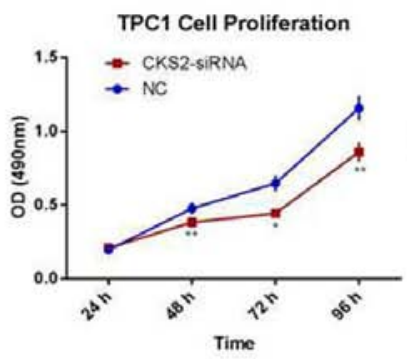

D
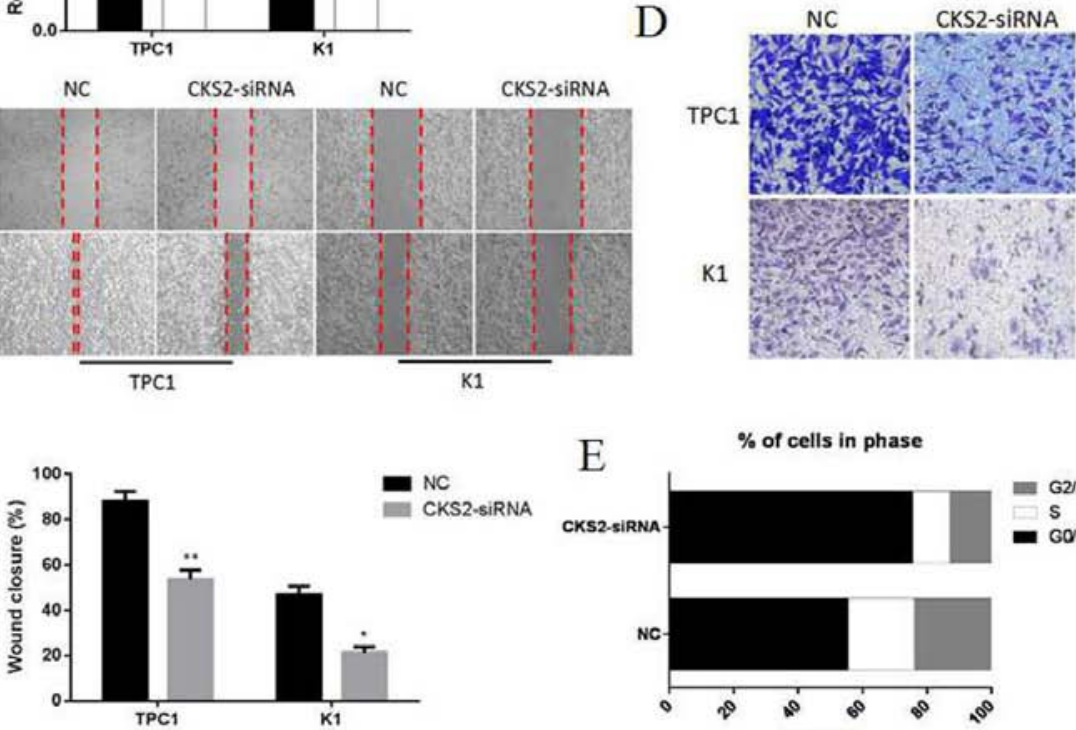

E

$\%$ of cells in phase

cors:aripun

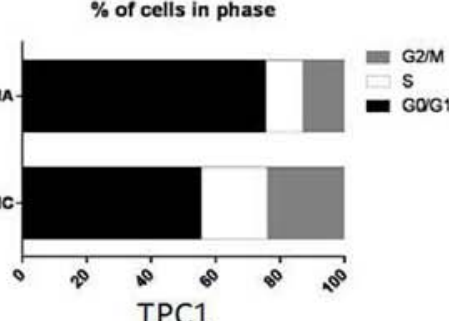

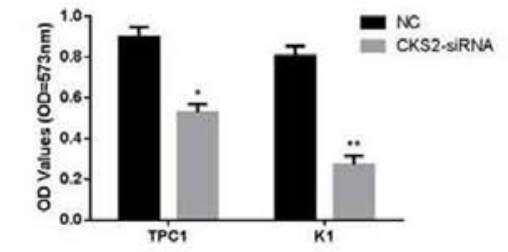
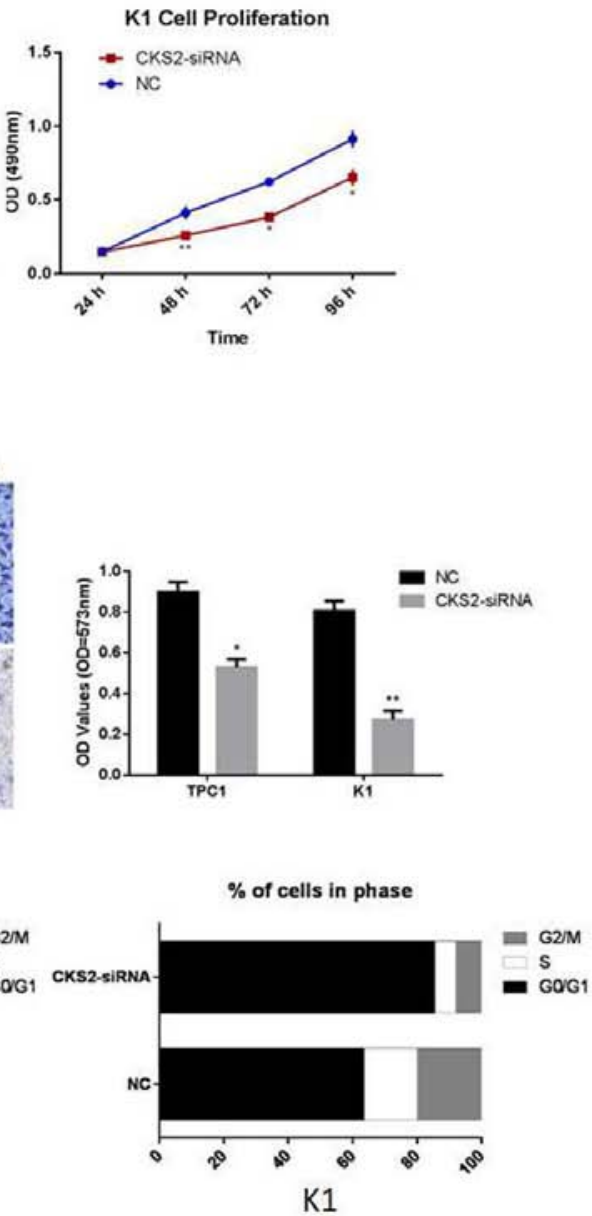

Figure 7. Effects of CKS2 in thyroid papillary cancer cell proliferation, migration, invasion and cell cycle. (A) The level of CKS2 protein was decreased in CKS2-siRNA group compared with NC group in TPC1 and K1 cells. ${ }^{* * *} \mathrm{P}<0.001$ vs. NC. (B) Cells transfected with CKS2-siRNA showed markedly inhibited cell proliferation compared with $\mathrm{NC}$. ${ }^{*} \mathrm{P}<0.05,{ }^{* *} \mathrm{P}<0.01$ vs. $\mathrm{NC}$. (C and $\left.\mathrm{D}\right)$ Inhibition of $\mathrm{CKS} 2$ inhibited the migration and invasion ability. ${ }^{*} \mathrm{P}<0.05,{ }^{* *} \mathrm{P}<0.01$ vs. NC. (E) Inhibition of CKS2 disrupted the cell cycle. $\mathrm{P}<0.05$ vs. NC.

western blotting. The results showed that miR-7 overexpression significantly reduced the CKS2 expression at protein levels. We also found that the downstream gene of CKS2, such as cyclin B1 and cdk1, can also be inhibited by miR-7 and CKS2 axis at the protein level (Fig. 6). At last, we investigated the role of CKS2 in thyroid papillary cancer. Silencing of CKS2 by CKS2-siRNA can inhibit proliferation, invasion, migration and induce G0/G1 cell cycle arrest in TPC1 and K1 thyroid papillary cancer cells (Fig. 7). Thus, our data indicated that miR-7 can regulate CKS2 and its downstream genes in thyroid papillary cancer.

\section{Discussion}

Thyroid papillary carcinoma is the most common form of follicular-cell derived carcinomas and comprises almost $75 \%$ of all newly-diagnosed thyroid cancers (21). Accumulating evidence indicates that the aberrant expression of miRNAs contributes to thyroid papillary carcinoma tumorigenesis and metastasis through repression of their target genes, suggesting that miRNAs may serve as molecular biomarkers for the prediction and prognosis of PTC, and as novel targets for disease treatment (22). Dysregulation of miRNAs is connected with initiation and progression of thyroid cancer, since they may serve as oncogenes or tumor suppressors. For example, upregulation of miR-146b significantly promoted cell migration and invasiveness and increased resistance to chemotherapy-induced apoptosis in thyroid papillary carcinoma (23). miR-34a can regulate growth arrest-specific 1 (GAS1) expression to promote proliferation and suppress apoptosis in thyroid papillary cancer cells via the PI3K/Akt/ Bad pathway (24). In this study, we are interested in the role of miR-7 in thyroid papillary carcinoma and speculate CKS2 as one of its possible targets.

CKS2 is the member of cell cycle dependent protein kinase subunits family, which participates in cell cycle regulation (25-27). CKS2 plays an important role in the process of somatic cell division, it also exhibits certain functions in tumor development (28-30). It is reported that CKS2 is upregulated in many types of tumors, including prostate cancer, bladder cancer, breast cancer and liver cancer $(31,32)$. As the downstream genes of CKS2, cdk1 and cyclin B1 are known to be important players in the cell cycle. Many studies have demonstrated that cyclin B1-cdk1 protein kinase, also known as mitosis promoting factor (MPF), is essential for mitosis and that in its absence, cells are unable to progress past the G2 
phase of the cell cycle, CKS2 binds to cdk1 via interaction with the catalytic subunit of cdk1, and subsequently affects cell cycle (33). Many human malignancies are characterized by CKS2 overexpression, and it is generally known as an oncogene. However, the underlying cellular functions of CKS2 in thyroid papillary carcinoma and related mechanisms remain largely unexplored.

In our experiment, miRNA-microarray was firstly performed in thyroid papillary cancer specimens, miR-7 was significantly decreased in cancer tissues compared to paracancer tissues. To validate the result in miRNA-microarray, we investigated the expression levels of miR-7 in 20-paired thyroid papillary cancer and adjacent normal specimens. Interestingly, we observed that the expression levels of miR-7 were also remarkably decreased in cancer tissues relative to paired non-tumor tissues. Since miR-7 has been described as a tumor suppressor gene in several human cancers including glioblastoma (34), hepatocellular carcinoma (16) and lung cancer (35), we hypothesized that miR-7 might be a novel tumor-suppressor miRNA in thyroid papillary cancer. Then we investigated the specific role of miR-7 in two typical thyroid papillary cancer cell lines, TPC1 and K1. Cells were transfected with miR-7 mimics or miR-NC respectively to detect the effects on various aspects of thyroid cancer biology. Our results showed that the exogenous overexpression of miR-7 regulating by miR-7 mimics inhibited proliferation and colony formation ability of thyroid papillary cancer cells as measured by MTT and colony formation assays. Moreover, cell migration and invasion ability was also significantly inhibited by overexpression of miR-7. We also found that miR-7 can distinctly induce G0/G1 cell cycle arrest. We tried to explore the correlation between the expression levels of miR-7 and CKS2 in clinical thyroid papillary cancer specimens. As expected, a negative correlation was observed between these two variables. Luciferase reporter assay identified that miR-7 could directly bind to the 3'-UTR of CKS2 . In order to further explore the molecular mechanism of the growth inhibition induced by miR-7, we examined its effect on the expression of a panel of CKS2 downstream genes, namely cyclin B1, cyclin A and cdk1. Western blot assays demonstrated that miR-7 was able to downregulate CKS2 protein, cyclin $\mathrm{B} 1$ protein and cdk1 protein. We concluded that knockdown of endogenous CKS2 can mimic the result of miR-7 upregulation in thyroid papillary cancer cells Collectively, the experimental results showed that miR-7 inhibits the proliferation, migration and invasion of thyroid papillary cancer cells via targeting CKS2.

In recent years, several studies on miR-7 and cancer were accomplished. It has been confirmed as a tumor-suppressor factor in multiple cancers including those associated with poor outcomes such as glioblastoma (34), non-small cell lung cancer (35) and gastric cancer (36) as well as some endocrine related cancers such as breast, prostate and ovarian cancer (37). Glover et al found that miR-7 regulates adrenocortical carcinoma by targeting multiple cell pathways and miR-7 replacement therapy is effective in reducing tumor growth (38). Additionally, they also demonstrated that miR-7 therapy in vivo could lead to inhibition of cdk1, which is partially consistent with our findings. In this experiment, we also tried to explore the relationship between clinical data and miR-7 levels. The tumor size and the number of metastatic lymph nodes was found to have a negatively correlation with the relative miR-7 expression in our cases, which suggested that miR-7 might be a reliable biological marker in diagnosis of thyroid papillary carcinoma. Since this is a pattern verified only in 20 clinical cases, the reliability is relatively low and needs to be confirmed in a larger number of samples.

In conclusion, our findings demonstrate that miR-7 is downregulated in papillary thyroid carcinoma tissues and cell lines. This study also provides novel evidence that in a model of papillary thyroid carcinoma, upregulation of miR-7 inhibits cellular growth, suppresses cellular migration and invasion, induces a G0/G1 arrest likely by targeting CKS2 and ultimately regulating the expression of cyclinB1 and cdk, which could be considered as a basis for the development of miRNA-targeted therapies for papillary thyroid carcinoma.

\section{Acknowledgements}

This study was supported by grants from National Natural Science Foundation of China (no. 82172240). We sincerely thank all the teachers at the Central Laboratory of the Shanghai Tenth People's Hospital for their support.

\section{References}

1. Zhang J, Wang Y, Li D and Jing S: Notch and TGF- $\beta /$ Smad3 pathways are involved in the interaction between cancer cells and cancer-associated fibroblasts in papillary thyroid carcinoma. Tumour Biol 35: 379-385, 2014.

2. Lloyd RV, Buehler D and Khanafshar E: Papillary thyroid carcinoma variants. Head Neck Pathol 5: 51-56, 2011.

3. Silver CE, Owen RP, Rodrigo JP, Rinaldo A, Devaney KO and Ferlito A: Aggressive variants of papillary thyroid carcinoma. Head Neck 33: 1052-1059, 2011.

4. Scheumann GF, Gimm O, Wegener G, Hundeshagen $\mathrm{H}$ and Dralle H: Prognostic significance and surgical management of locoregional lymph node metastases in papillary thyroid cancer. World J Surg 18: 559-567, discussion 567-568, 1994.

5. Mazzaferri EL and Kloos RT: Clinical review 128: Current approaches to primary therapy for papillary and follicular thyroid cancer. J Clin Endocrinol Metab 86: 1447-1463, 2001.

6. Pellegriti G, Scollo C, Lumera G, Regalbuto C, Vigneri R and Belfiore A: Clinical behavior and outcome of papillary thyroid cancers smaller than $1.5 \mathrm{~cm}$ in diameter: Study of 299 cases. J Clin Endocrinol Metab 89: 3713-3720, 2004.

7. Grant CS: Recurrence of papillary thyroid cancer after optimized surgery. Gland Surg 4: 52-62, 2015.

8. Lin X, Guan H, Li H, Liu L, Liu J, Wei G, Huang Z, Liao Z and Li Y: miR-101 inhibits cell proliferation by targeting Rac1 in papillary thyroid carcinoma. Biomed Rep 2: 122-126, 2014.

9. Bartel DP: MicroRNAs: Target recognition and regulatory functions. Cell 136: 215-233, 2009.

10. Esquela-Kerscher A and Slack FJ: Oncomirs - microRNAs with a role in cancer. Nat Rev Cancer 6: 259-269, 2006.

11. He L and Hannon GJ: MicroRNAs: Small RNAs with a big role in gene regulation. Nat Rev Genet 5: 522-531, 2004.

12. Chen YT, Kitabayashi N, Zhou XK, Fahey TJ III and Scognamiglio T: MicroRNA analysis as a potential diagnostic tool for papillary thyroid carcinoma. Mod Pathol 21: 1139-1146, 2008.

13. Kong X, Li G, Yuan Y, He Y, Wu X, Zhang W, Wu Z, Chen T, Wu W, Lobie PE, et al: MicroRNA-7 inhibits epithelial-tomesenchymal transition and metastasis of breast cancer cells via targeting FAK expression. PLoS One 7: e41523, 2012.

14. Li J, Zheng Y, Sun G and Xiong S: Restoration of miR-7 expression suppresses the growth of Lewis lung cancer cells by modulating epidermal growth factor receptor signaling. Oncol Rep 32: 2511-2516, 2014.

15. Hansen TB, Kjems J and Damgaard CK: Circular RNA and miR-7 in cancer. Cancer Res 73: 5609-5612, 2013. 
16. Fang Y, Xue JL, Shen Q, Chen J and Tian L: MicroRNA-7 inhibits tumor growth and metastasis by targeting the phosphoinositide 3-kinase/Akt pathway in hepatocellular carcinoma. Hepatology 55: 1852-1862, 2012

17. Demetrick DJ, Zhang H and Beach DH: Chromosomal mapping of the human genes CKS1 to 8q21 and CKS2 to 9q22. Cytogenet Cell Genet 73: 250-254, 1996.

18. Urbanowicz-Kachnowicz I, Baghdassarian N, Nakache C, Gracia D, Mekki Y, Bryon PA and French M: ckshs expression is linked to cell proliferation in normal and malignant human lymphoid cells. Int J Cancer 82: 98-104, 1999.

19. Lv M, Zhang X, Li M, Chen Q, Ye M, Liang W, Ding L, Cai H, $\mathrm{Fu} \mathrm{D}$ and Lv Z: miR-26a and its target CKS2 modulate cell growth and tumorigenesis of papillary thyroid carcinoma. PLoS One 8: e67591, 2013.

20. Pallante P, Visone R, Ferracin M, Ferraro A, Berlingieri MT, Troncone G, Chiappetta G, Liu CG, Santoro M, Negrini M, et al: MicroRNA deregulation in human thyroid papillary carcinomas. Endocr Relat Cancer 13: 497-508, 2006

21. Ban Y, Yamamoto G, Takada M, Hayashi S, Ban Y, Shimizu K, Akasu H, Igarashi T, Bando Y, Tachikawa T, et al: Proteomic profiling of thyroid papillary carcinoma. J Thyroid Res 2012: 815079, 2012.

22. Aragon Han $\mathrm{P}$, Weng $\mathrm{CH}$, Khawaja HT, Nagarajan $\mathrm{N}$, Schneider EB, Umbricht CB, Witwer KW and Zeiger MA MicroRNA expression and association with clinicopathologic features in papillary thyroid cancer: A systematic review. Thyroid 25: 1322-1329, 2015

23. Chou CK, Yang KD, Chou FF, Huang CC, Lan YW, Lee YF, Kang HY and Liu RT: Prognostic implications of miR-146b expression and its functional role in papillary thyroid carcinoma. J Clin Endocrinol Metab 98: E196-E205, 2013.

24. Ma Y, Qin H and Cui Y: miR-34a targets GAS1 to promote cell proliferation and inhibit apoptosis in papillary thyroid carcinoma via PI3K/Akt/Bad pathway. Biochem Biophys Res Commun 441: 958-963, 2013.

25. Pines J: Cell cycle: Reaching for a role for the Cks proteins. Curr Biol 6: 1399-1402, 1996.

26. Spruck CH, de Miguel MP, Smith AP, Ryan A, Stein P, Schultz RM, Lincoln AJ, Donovan PJ and Reed SI: Requirement of Cks2 for the first metaphase/anaphase transition of mammalian meiosis. Science 300: 647-650, 2003.

27. Frontini M, Kukalev A, Leo E, Ng YM, Cervantes M, Cheng CW, Holic R, Dormann D, Tse E, Pommier Y, et al: The CDK subunit CKS2 counteracts CKS1 to control cyclin A/CDK2 activity in maintaining replicative fidelity and neurodevelopment. Dev Cell 23: 356-370, 2012.
28. Martinsson-Ahlzén HS, Liberal V, Grünenfelder B, Chaves SR, Spruck $\mathrm{CH}$ and Reed SI: Cyclin-dependent kinase-associated proteins Cks1 and Cks2 are essential during early embryogenesis and for cell cycle progression in somatic cells. Mol Cell Biol 28: 5698-5709, 2008.

29. Chen R, Feng C and Xu Y: Cyclin-dependent kinase-associated protein Cks2 is associated with bladder cancer progression. J Int Med Res 39: 533-540, 2011.

30. Kita Y, Nishizono Y, Okumura H, Uchikado Y, Sasaki K, Matsumoto M, Setoyama T, Tanoue K, Omoto I, Mori S, et al: Clinical and biological impact of cyclin-dependent kinase subunit 2 in esophageal squamous cell carcinoma. Oncol Rep 31: 1986-1992, 2014

31. Wang J, Xu L, Liu Y, Chen J, Jiang H, Yang S and Tan H: Expression of cyclin kinase subunit 2 in human breast cancer and its prognostic significance. Int J Clin Exp Pathol 7: 8593-8601, 2014.

32. Shen DY, Fang ZX, You P, Liu PG, Wang F, Huang CL, Yao XB, Chen ZX and Zhang ZY: Clinical significance and expression of cyclin kinase subunits 1 and 2 in hepatocellular carcinoma. Liver Int 30: 119-125, 2010.

33. Dorée $\mathrm{M}$ and Hunt T: From $\mathrm{Cdc} 2$ to $\mathrm{Cdk} 1$ : When did the cell cycle kinase join its cyclin partner? J Cell Sci 115: 2461-2464, 2002.

34. Kefas B, Godlewski J, Comeau L, Li Y, Abounader R, Hawkinson M, Lee J, Fine H, Chiocca EA, Lawler S, et al: MicroRNA-7 inhibits the epidermal growth factor receptor and the Akt pathway and is down-regulated in glioblastoma. Cancer Res 68: 3566-3572, 2008.

35. Xiong S, Zheng Y, Jiang P, Liu R, Liu X and Chu Y: MicroRNA-7 inhibits the growth of human non-small cell lung cancer A549 cells through targeting BCL-2. Int J Biol Sci 7: 805-814, 2011.

36. Zhao X, Dou W, He L, Liang S, Tie J, Liu C, Li T, Lu Y, Mo P, Shi Y, et al: MicroRNA-7 functions as an anti-metastatic microRNA in gastric cancer by targeting insulin-like growth factor-1 receptor. Oncogene 32: 1363-1372, 2013.

37. Kalinowski FC, Brown RAM, Ganda C, Giles KM, Epis MR, Horsham $\mathrm{J}$ and Leedman PJ: MicroRNA-7: A tumor suppressor miRNA with therapeutic potential. Int J Biochem Cell Biol 54: 312-317, 2014.

38. Glover AR, Zhao JT, Gill AJ, Weiss J, Mugridge N, Kim E, Feeney AL, Ip JC, Reid G, Clarke S, et al: MicroRNA-7 as a tumor suppressor and novel therapeutic for adrenocortical carcinoma. Oncotarget 6: 36675-36688, 2015. 